\title{
COVID-19: be aware of contaminated airway devices
}

\author{
Asuka Fujishiro ${ }^{1} \cdot$ Tomoyuki Saito $^{1} \cdot$ Takashi Asai $^{1}$ \\ Received: 6 August 2020 / Accepted: 21 August 2020 / Published online: 11 September 2020 \\ (c) Japanese Society of Anesthesiologists 2020
}

Keywords COVID-19 · Contamination · Airway devices

To the Editor:

Airway management should now always be regarded as a high risk of staff becoming infected with COVID-19, as viral aerosol may be coming out even from an asymptomatic patient. Guidelines and expert recommendations [1-3] recommend several practical methods to minimize infection of the staff by viral aerosol, but we believe that less attention is being paid to handling airway devices used.

Previously, we placed the used airway devices (in particular, a facemask) on an anesthesia cart (Fig. 1a), on an operating table, or even on an anesthesia machine, without much attention to contamination. This practice has a potential risk of staff being infected from touching a contaminated surface. To rectify this problem, we now routinely use a tray, which is placed on a cart, positioned near the patient's head, during induction of anesthesia (and emergency from anesthesia), and all the airway devices are placed immediately after use in this tray. After operation, each device is either disposed or disinfected, and the tray is sterilized by autoclave. We believe that this practice would further minimize the risk of infection of staff, by avoiding contamination of surroundings, and by helping reduce direct handling of contaminated devices.
Tomoyuki Saito

s-tomo@dokkyomed.ac.jp

1 Department of Anesthesiology, Dokkyo Medical University

Saitama Medical Center, 2-1-50 Minamikoshigaya,

Koshigaya City, Saitama 343-8555, Japan 
Fig. 1 Placement of used airway devices. a Previously, used airway devices were placed on an anesthesia table without much attention to contamination. $\mathbf{b}$ Currently, all the devices are placed immediately after use in an autoclavable tray

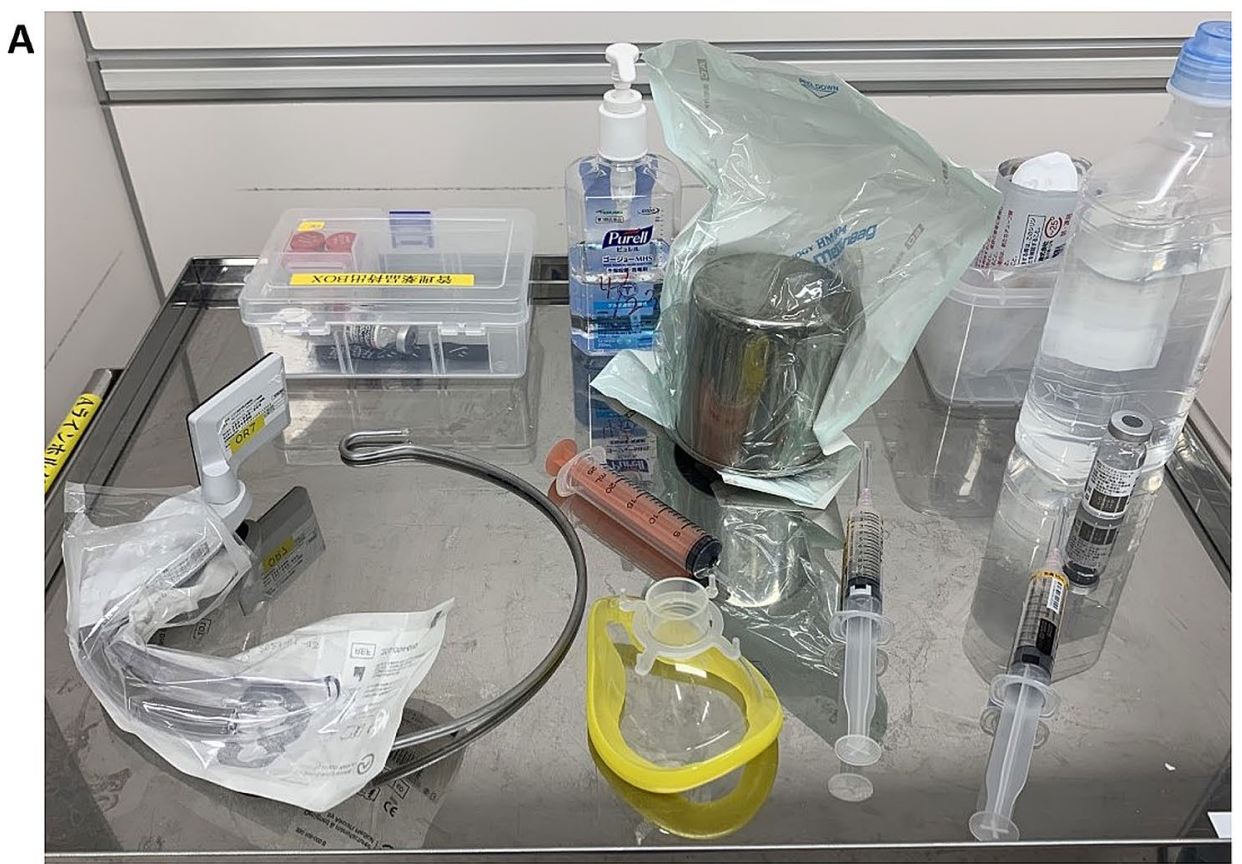

B

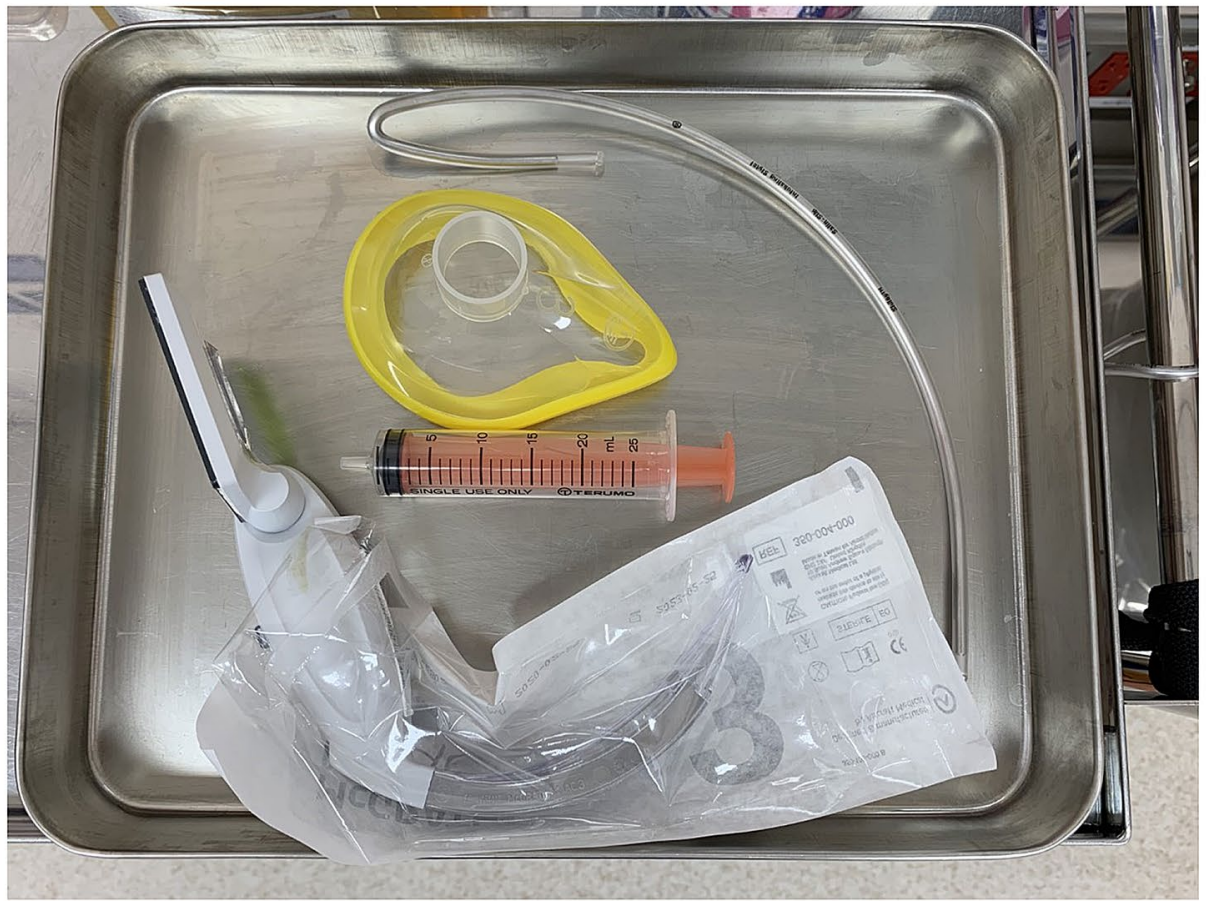

Funding None.

\section{Compliance with ethical standards}

\section{Conflict of interest None.}

\section{References}

1. Yamakage M. Anesthesia in the times of COVID-19. J Anesth. 2020. https://doi.org/10.1007/s00540-020-02798-4.

2. Peng PWH, Ho P-L, Hota SS. Outbreak of a new coronavirus: what anaesthetists should know. Br J Anaesth. 2020;124:497-501.

3. Au Yong PS, Chen X. Reducing droplet spread during airway manipulation: lessons from COVID-19 pandemic in Singapore. Br J Anaesth. 2020;125:e176-e178178.

Publisher's Note Springer Nature remains neutral with regard to jurisdictional claims in published maps and institutional affiliations. 